beneath the upper and lower lids.) Miss Ida Mann's suggestion (mentioned in the Journal, March 1939, p. 191) and Dr. Culler's evidence (January, 1939) strongly indicated that the word "developmental" should be dropped. As Dr. Culler pointed out, all the patients so far recorded with this condition have been elderly.

I may take this opportunity to add that I am now aware of a possible reason for having, in my original article, overlooked this characteristic age-incidence and so for having allowed myself to suggest that the condition was "developmental." In the original article (October, 1937) I mentioned the memory of some cases which I had come upon some dozen or more years before, the records of which I had destroyed. I then had a definite idea that amongst these few previous cases was one of a girl aged about 8 years. This patient, now aged about 24 years, came back to me recently. I had not seen her since she was eight, and her mother reminded me why she had brought her child to me some sixteen years ago. In each eye, on the mesial side, a hole in the sclera for the transmission of a perforating artery was very conspicuous, being much larger than normal and dark, especially in one eye. Her mother had noticed this one day and had brought her to me because she thought there was an embedded foreign body. I had then (sixteen years ago) made notes of this case which were put away among the various "slit-lamp" records which I destroyed later. Thus, I think, did a memory of this case, unrelated to scleral plaques, influence me when writing my description in October 1937 and lead me to think that they could occur in a child.

I have entitled this present communication "bilateral deficiency" only for the sake of continuity of reference. Clearly Dr. Culler's term " scleral plaques" is more suitable, and I would propose to use it, and to drop the former term, should I have occasion to make any future reference to this condition.

\title{
ANNOTATION
}

\section{Dangerous Drugs in War-time}

"You alarm me!" said the King. "I feel faint--Give me a ham sandwich!"..." another sandwich!" said the King. ... "Hay, then," the King murmured in a faint whisper. ... " There's nothing like eating hay when you're faint," he remarked to Alice as he munched away. Alice, it will be remembered, suggested that cold water, or some sal-volatile would be better. "I did'nt say there was nothing better," the King replied, "I said there was nothing like it." 
This scene came into our mind when we went to the chemist to order some morphia in view of the possibility of being called upon to render first aid to air-raid casualties. We were surprised when we were told that to those retired from active practice morphia could not be supplied on their own prescriptions. It is apparently a punishable offence for a chemist to supply morphia, cocaine, or any other "dangerous drug" to a qualified medical man or woman if he or she has retired from practice. In our opinion it is high time, in the present emergency, that this embargo on the provision of drugs should be lifted. Ophthalmic surgeons do not often have to prescribe morphia for their patients, but cocaine is one of our sheet anchors, and it is a monstrous interference with professional liberty that, because we happen to be no longer competing with other physicians and surgeons, we should be debarred from obtaining the drugs that we may need in an emergency. And as morphia is more often than not urgently needed in the severe types of injury inflicted, no restrictions should be placed in the way of its provision to qualified persons.

\section{ABSTRACTS}

\section{MISCELLANEOUS}

(1) Dandy, Walter E. (Baltimore).-Papilloedema without intracranial pressure (optic neuritis). Annals of Surgery, August, 1939.

(1) A series of cases, in which bilateral papilloedema with raised intracranial pressure and yet no brain tumour was present, was published by Dandy in the Annals of Surgery in 1937 and abstracted in our pages, Vol. XXII, p. 244. The present paper deals with another, even larger, group of cases having papilloedema, usually bilateral, but occasionally unilateral, frequently fundus haemorrhages with mild degree of headache and varying degrees of visual loss. The present group differs from the former in the absence of increased intra-cranial pressure.

Forty-four cases are included in this report and the end-results of 31 ; from the remaining 13 cases no answer has been received to inquiries by letter. The cases are spread over the past 15 years. Females were almost three times as frequently affected as males and cases occurred in every decade of life up to the 70th year.

The following are the author's conclusions : 